\title{
Temperature Dependence of the Absorption Spectra of Nitrogen Oxide, Nitrogen Dioxide and Sulfur Dioxide in the Application of Differential Optical Absorption Spectroscopy*
}

\author{
J. Mellqvist† and A. Rosén \\ Department of Physics, Chalmers University of Technology and University of Göteborg, S-412 96 \\ Göteborg, Sweden
}

H. Axelsson

Swedish Environmental Research Institute (IVL), P.O. Box 47086, S-402 58 Göteborg, Sweden

\begin{abstract}
An experimental set-up has been designed for measurements of differential absorption cross-sections of gases at different temperatures. Preliminary measurements on $\mathrm{NO}, \mathrm{NO}_{2}$ and $\mathrm{SO}_{2}$ have been carried out at temperatures between 20 and $400^{\circ} \mathrm{C}$ by using spectral resolutions in the range $0.26-0.95 \mathrm{~nm}$. These measurements show that the differential absorption cross-sections for all three gases decrease continuously with increasing temperature. Large relative errors resulted when differential absorption cross-sections obtained at room temperature were used in the differential optical absorption spectroscopic technique for evaluation of the concentration of gases at high temperatures. The relative errors were of the order of $70 \%$ for $\mathrm{SO}_{2}$ and $\mathrm{NO}_{2}$ and of the order of $20 \%$ for $\mathrm{NO}$ at $400{ }^{\circ} \mathrm{C}$.
\end{abstract}

Keywords: Differential absorption; nitrogen oxide; nitrogen dioxide; sulfur dioxide; temperature effects

Differential optical absorption spectroscopy (DOAS) is a quantitative optical measuring technique for gases absorbing in the ultraviolet (UV) and visible spectral regions. ${ }^{1}$ The technique is based on the recording of differential absorption, i.e., the difference between local maxima and minima in the absorption spectrum of the probed gas. In the application of DOAS, the light from a broad-band xenon high-pressure lamp is transmitted through the atmosphere for distances of up to several kilometres. The light is received and analysed by use of a fast-scanning device (dispersive spectrometer) to eliminate the influence of air turbulence. The DOAS technique has been used to monitor a wide variety of atmospheric gases, e.g., $\mathrm{NO}_{2}, \mathrm{SO}_{2}, \mathrm{NO}, \mathrm{NH}_{3}, \mathrm{HNO}_{2}$ and $\mathrm{O}_{3} .{ }^{2}$ An interesting application of DOAS would be to use it for the monitoring of flue gas emissions. A straightforward application of the technique is, however, not justified as the flue gases have high temperatures, which could significantly affect the differential absorption cross-sections. In addition, the measurement pathlength is not variable, which could lead, at high gas concentrations, to a much higher differential absorption than is usually preferred $(1 \%)$.

Preliminary measurements of the differential absorption cross-sections of $\mathrm{NO}, \mathrm{NO}_{2}$ and $\mathrm{SO}_{2}$ in the temperature range expected in a flue gas $\left(20-400^{\circ} \mathrm{C}\right)$ were therefore undertaken. In this paper, the experimental equipment is described and some preliminary results are presented. Measurements were also carried out at high concentrations (large differential absorption) to verify the region of linearity of DOAS for measurements on $\mathrm{NO}, \mathrm{SO}_{2}$ and $\mathrm{NO}_{2}$. These results will be published in a later paper, together with more extensive measurements and calculations of the temperature dependence of the differential absorption cross-sections.

\section{Experimental}

The experimental set-up is shown in Fig. 1. Light from a 150 W xenon arc lamp (Hamamatsu L2273) was transmitted through a $1.19 \mathrm{~m}$ long stainless-steel measurement cylinder

\footnotetext{
* Presented at the XXVII Colloquium Spectroscopicum Internationale (CSI), Bergen, Norway, June 9-14, 1991.

$\dagger$ Also at the Swedish Environmental Research Institute (IVL), P.O. Box 47086, S-402 58 Göteborg. Sweden.
}

(i.d. $0.105 \mathrm{~m}$ ) and then focused onto the entrance slit of a Jarrell-Ash spectrometer ( $275 \mathrm{~mm}, \mathrm{f} / 3.8$ Czerny-Turner). The spectrometer was equipped with a rotating slotted disc set-up, replacing the exit slit. ${ }^{3}$ The measurement time for each scan of the spectrum was $10 \mathrm{~ms}$. Three different gratings were used with grating constants of 2400,1200 and 600 grooves $\mathrm{mm}^{-1}$ and these were blazed at 260,300 and $300 \mathrm{~nm}$, respectively. The width of the entrance slit was $100 \mu \mathrm{m}$ and the slotted disc on the exit side had $100 \mu \mathrm{m}$ slits. The best spectral resolution was $0.26 \mathrm{~nm}$ in the central part of the spectrum. The spectral resolution decreased, however, to $0.34 \mathrm{~nm}$ at both ends of the spectrum owing to slightly tilted slits in these parts of the scan. The spectrum was masked in the focal plane to cover approximately $24 \mathrm{~nm}$ when the best resolution was used. An EMI $9750 \mathrm{QA}$ photomultiplier tube was used as the detector, and the signal was amplified and passed to an IBM-compatible AT computer with a custom-made multichannel analyser plug-in card with a 12-bit analogue-to-digital converter, dividing each scan into 100 channels. After sampling of $2 \times 10^{4}$ scans over a period of $5 \mathrm{~min}$, the data were transferred to the computer for signal processing.

The measurement cylinder was placed in a heat-pipe oven that could be maintained in the range $20-500^{\circ} \mathrm{C}$. The temperature was measured at three places inside the cylinder,

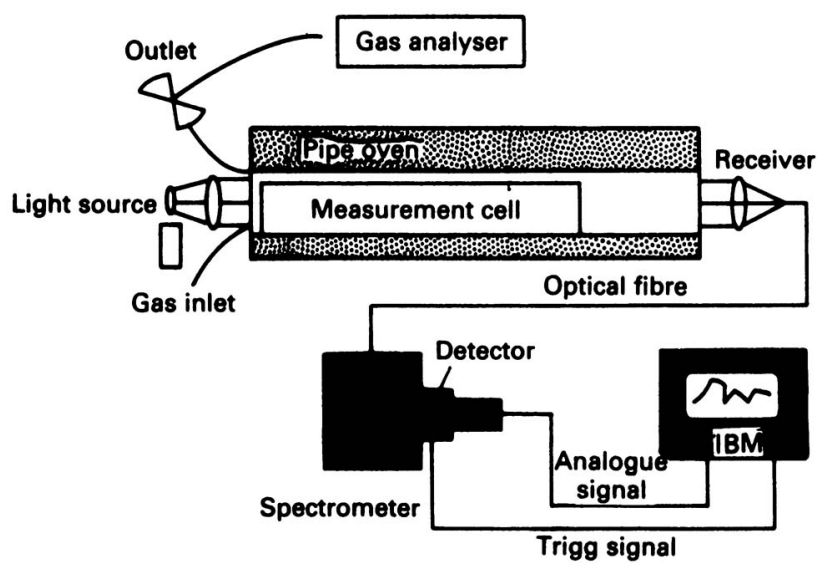

Fig. 1 Experimental set-up used for measurements of the differential absorption cross-sections of gases at different temperatures 


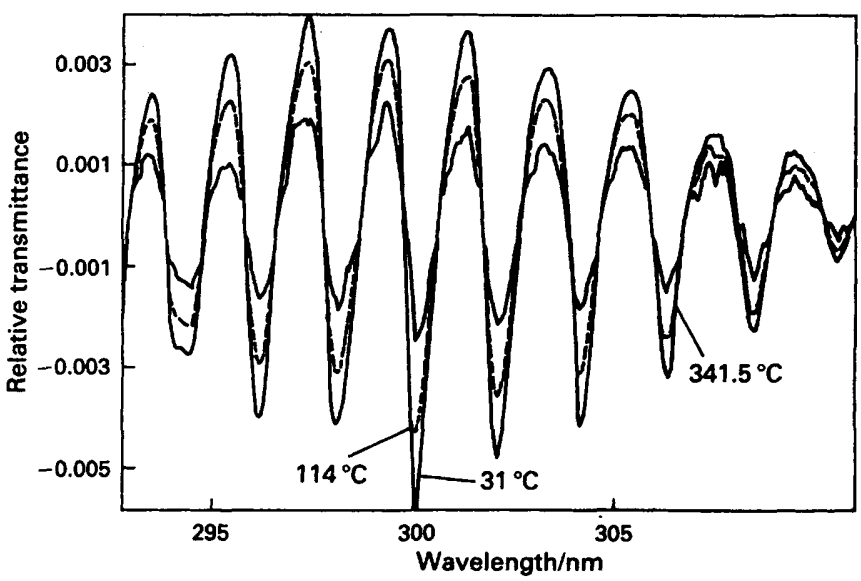

Fig. 2 Differential absorbance (e) of $\mathrm{SO}_{2}$ around $300 \mathrm{~nm}$ at three different temperatures, 31,114 and $341.5^{\circ} \mathrm{C}$. Resolution, $0.5 \mathrm{~nm}$. The concentration is normalized to $15.00 \mathrm{mg} \mathrm{m}^{-3}$ of $\mathrm{SO}_{2}$ in the measurement cell

at both ends and in the middle, by using type- $\mathrm{K}$ thermocouples. The gas was pre-heated in a stainless-steel tube (i.d. $4.35 \mathrm{~mm}$ ) before it entered the measurement cylinder. At the outlet of the measurement cylinder the static pressure was measured by using a differential pressure gauge, together with a mercury barometer. The gases investigated were delivered from AGA in Sweden at specific volume concentrations. They were all diluted in nitrogen with a precision of $2 \% \mathrm{v} / \mathrm{v}$. These gases were additionally diluted with use of a mass-flow instrument (Environics 100). The gases were analysed at the outlet of the measurement cylinder by conventional monitors. A fluorescence instrument (Monitor Laboratories 8850) was used for $\mathrm{SO}_{2}$ and a combined infrared and UV absorption instrument (BINOS) for $\mathrm{NO}_{2}$ and NO. The determination of the differential absorption cross-sections for $\mathrm{NO}, \mathrm{NO}_{2}$ and $\mathrm{SO}_{2}$ in the application of DOAS was carried out according to the algorithms described by Platt and Perner. ${ }^{3}$

\section{Measurements}

Measurements of the differential absorption cross-sections of $\mathrm{NO}, \mathrm{NO}_{2}$ and $\mathrm{SO}_{2}$ were carried out at nine temperatures between 20 and $400^{\circ} \mathrm{C}$ at pressures close to atmospheric. Different spectral resolutions $(0.26-0.98 \mathrm{~nm})$ and gas concentrations $(5-200 \mathrm{ppm}, \mathrm{v} / \mathrm{v})$ were used. The measurements were performed dynamically by passing gases continuously (2-81 $\min ^{-1}$ ), at known volume concentrations, through the measurement cylinder. In this way, wall effects (adsorption/ dissociation) were suppressed. Nitrogen oxide was measured around $226 \mathrm{~nm}, \mathrm{SO}_{2}$ around $300 \mathrm{~nm}$ and $\mathrm{NO}_{2}$ around $430 \mathrm{~nm}$. In order to avoid photodissocation of the absorption gases, optical filters were used for $\mathrm{SO}_{2}$ and $\mathrm{NO}_{2}$, with cut-off wavelengths at 240 and $397.5 \mathrm{~nm}$, respectively. The absolute values of the differential absorption cross-section were obtained by calculating the true number density in the measurement cell by using the ideal gas law. By correlating the differential absorption cross-sections at all measured temperatures with the differential absorption cross-section at room temperature, values of the influence of temperature on DOAS were quantified for each gas.
Table 1 Maximum relative errors (\%) of the measured gas concentrations at different temperatures, obtained by using DOAS with differential absorption cross-sections determined at room temperature. The spectral resolution was $0.26 \mathrm{~nm}$

\begin{tabular}{ccccc}
$\begin{array}{c}\text { Measured } \\
\text { gas }\end{array}$ & $\begin{array}{c}\text { Concen- } \\
\text { tration } \\
(\mathrm{ppm})\end{array}$ & $150^{\circ} \mathrm{C}$ & $300^{\circ} \mathrm{C}$ & $400^{\circ} \mathrm{C}$ \\
$\mathrm{NO}$ & 11 & 7 & 15 & 20 \\
$\mathrm{NO}_{2}$ & 120 & 40 & 60 & 75 \\
$\mathrm{SO}_{2}$ & 6 & 30 & 50 & 65 \\
\hline
\end{tabular}

\section{Results and Discussion}

The recorded experimental data show that the magnitude of the differential absorption cross-sections for $\mathrm{NO}_{2}, \mathrm{NO}$ and $\mathrm{SO}_{2}$ is strongly dependent on the temperature. The differential absorbance $(e)$ (differential absorption cross-section $\times$ concentration $\times$ pathlength) for $\mathrm{SO}_{2}$ at three temperatures $\left(31,114\right.$ and $\left.341.5^{\circ} \mathrm{C}\right)$ is shown in Fig. 2. The concentration was normalized to $15.00 \mathrm{mg} \mathrm{m}^{-3}$ by the use of the ideal gas law. It can be seen that when the temperature increases continuously, the magnitude of the differential absorption cross-section decreases continuously, i.e., the absorption at the peaks decreases while the absorption at the troughs increases. The measured temperature dependence at $114^{\circ} \mathrm{C}$ was in close agreement with that reported by Woods et al. ${ }^{4}$

Considerable errors in evaluated concentration from a DOAS measurement could therefore arise owing to the effects of temperature, as shown in Table 1 . These values were obtained by using differential absorption cross-sections, determined at room temperature, for evaluation of the gas concentrations in the measurement cylinder at different temperatures. No quantitative effect was observed with variation of the spectral resolution $(0.26-0.95 \mathrm{~nm})$, although the correlation between temperature and magnitude of the error was more clearly defined at higher spectral resolutions. The observed temperature dependence followed a continuous function. Hence, in practice, one should be able to compensate for the temperature dependence. This would require empirically defining the temperature dependence function, and adequately monitoring the flue gas temperature. Results depicting the correlation between temperature and magnitude of the error for $\mathrm{NO}, \mathrm{NO}_{2}$ and $\mathrm{SO}_{2}$ are also qualitatively verified by theoretical calculations for NO. ${ }^{5}$

This work was supported financially by the Thermal Engineering Research Association, Sweden (Project No. B7-010/B7-020).

\section{References}

1 Platt. U., and Perner, P., Workshop on Optical and Laser Remote Sensing 1982, Monterey, LA, February 8-11.

2 Axelsson, H., Edner, H., Galle, B., Ragnarson, P., and Rudin, M., Appl. Spectrosc., 1990, 40, 1654.

3 Platt, U., and Perner, P., in Optical and Laser Remote Sensing. eds. Killinger, D. K., and Mooradian, A.. Springer Series on Optical Science, Berlin. 1983, vol. 39, p. 97.

4 Woods, P. T., Jolliffe. B. W., and Marx, B. R., Opt. Commun., $1980,33,281$.

5 Mellqvist, J., Axelsson. H.. and Rosén. A.. unpublished work.

Paper 1/02984C

Received June 18, 1991 Accepted October 21, 1991 